\section{Maximizing Adhesion of Auxin Solutions to Stem Cuttings Using Sodium Cellulose Glycolate}

\author{
Eugene K. Blythe ${ }^{1,3}$ \\ Mississippi State University, Coastal Research and Extension Center, South \\ Mississippi Branch Experiment Station, P.O. Box 193, Poplarville, MS 39470 \\ Jeff L. Sibley ${ }^{2}$ \\ Department of Horticulture, Auburn University, Auburn, AL 36849
}

Additional index words. sodium carboxymethylcellulose, basal quick-dip, plant growth regulators, adjuvants, root-promoting compounds, vegetative propagation

\begin{abstract}
Auxin solutions prepared with sodium cellulose glycolate (SCG; a thickening agent, also known as sodium carboxymethylcellulose) and applied to stem cuttings using a basal quick-dip extend the duration of exposure of cuttings to the auxin and have previously been shown to increase root number and/or total root length on stem cuttings of certain taxa. In a series of three experiments, $3.75-\mathrm{cm}$ stem sections (representing the bases of stem cuttings) of three ornamental plant taxa were dipped to a depth of $2.5 \mathrm{~cm}$ for $1 \mathrm{~s}$ in solutions prepared with selected rates of SCG using either deionized water or a $10 \%$ dilution of an alcohol-based rooting compound (Dip 'N Grow). Each stem section was weighed before and after being dipped in the solution. Regression equations were determined for each experiment and the rate of SCG providing the maximum ratio of SCG solution weight to stem piece weight was determined by setting the first derivative of the regression equation equal to zero. Maximum adhesion of solution was obtained using SCG at 13.35 to $13.71 \mathrm{~g} \cdot \mathrm{L}^{-1}$ with an average rate of $13.5 \mathrm{~g} \cdot \mathrm{L}^{-1}$.
\end{abstract}

A variety of methods may be used for applying auxin to stem cuttings with the basal quick-dip and the powder application methods being the most common in commercial propagation as a result of their speed and ease of practice (Blythe et al., 2007). The dilute soak method allows for use of lower auxin concentrations than the basal quick-dip and powder application methods; however, the dilute soak method requires additional time for treating cuttings (Blythe et al., 2007; Hartmann et al., 2002). Like the dilute soak method, the substrate application method involves exposure of cutting bases to lower concentrations of auxin over an extended period with rooting responses using the substrate application method being equal to, or better than, a basal quick-dip (Blythe et al., 2004).

Preparation of liquid auxin solutions with the thickening agent sodium cellulose glycolate (SCG) enhances adhesion of the auxin solutions to the bases of stem cuttings, thus increasing the duration of exposure to the auxin (Beeson, 2000; Blythe and Sibley, 2007;

Received for publication 29 June 2010. Accepted for publication 9 Aug. 2010.

We thank Guihong Bi, K.C. Lee, and Hamidou Sakhanokho for reviewing an early draft of the manuscript.

Approved for publication as Journal Article No. J-11834 of the Mississippi Agricultural and Forestry Experiment Station, Mississippi State University.

${ }^{1}$ Assistant Research Professor.

${ }^{2}$ Professor

${ }^{3}$ To whom reprint requests should be addressed; e-mail blythe@pss.msstate.edu.
Childs and Beeson, 2001). Cuttings of some taxa have exhibited an increase in root number and/or total root length with inclusion of SCG in the auxin solution (Blythe and Sibley, 2007).

SCG, also known as sodium carboxymethylcellulose, is used as a thickener, binder, emulsifier, stabilizer, and colloidal suspending agent in salad dressing, fruit pie fillings, baked goods, dietetic foods, and other products (Joint FAO/WHO Expert Committee on Food Additives, 1966). In agriculture, SCG has been used as a seed dressing for certain cereal crops (Gasanov and Magomedov, 2004), as a component of controlled-release fertilizer (Shavit et al., 1995), and as a spray adjuvant for plant production and protection chemicals (Kirk, 2003).

Findings from the current study were divided for presentation in two reports. A previous report by Blythe and Sibley (2007) focused on rooting stem cuttings using auxin solutions prepared with SCG. The present report focuses on determining the rate of SCG that will maximize adhesion of waterand alcohol-based solutions of auxin to stem cuttings using the basal quick-dip method.

\section{Materials and Methods}

Solutions of SCG were prepared by adding SCG powder (Dip-Gel; Dip 'N Grow, Inc., Clackamas, OR) to $20^{\circ} \mathrm{C}$ deionized (DI) water or an alcohol-based auxin solution (Dip 'N Grow Liquid Rooting Concentrate; Dip 'N Grow, Inc.) diluted to $10 \%$ using DI water with manual stirring. Solutions were allowed to set covered overnight at room temperature $\left(23{ }^{\circ} \mathrm{C}\right)$ to dissolve completely. Solutions for Expt. 1 were prepared with DI water only at SCG rates of $0,3,6,9,12,15,18,21,24$, or $27 \mathrm{~g} \cdot \mathrm{L}^{-1}$. Solutions for Expt. 2 were prepared with either DI water or diluted auxin solution with SCG rates of $11,12,13,14,15$, or $16 \mathrm{~g} \cdot \mathrm{L}^{-1}$. Solutions for Expt. 3 were prepared with diluted Dip 'N Grow only with SCG at the same rates used in Expt. 2.

For Expt. 1, internodal stem sections were prepared from actively growing, softwood shoots collected from greenhouse-grown plants of Hedera helix. For Expt. 2, stem sections without nodes were prepared from semihardwood shoots of Ternstroemia gymnanthera collected from the most recently matured flush of growth of a landscape-grown plant. For Expt. 3, stem sections with a single node at the proximal end (with the leaf removed at its point of connection to the stem) were prepared from semihardwood shoots of Elaeagnus xebbingei collected from the most recently matured flush of growth of a landscape-grown plant. All stem sections were selected to be of similar diameter within each species, prepared $3.75 \mathrm{~cm}$ in length, and marked with a fine-point marking pen at a point $2.5 \mathrm{~cm}$ from the proximal end to facilitate dipping the stem pieces into solutions to a uniform depth.

Each stem piece was individually weighed on an analytic balance to $0.1 \mathrm{mg}$, dipped into a SCG solution to a depth of $2.5 \mathrm{~cm}$ for $1 \mathrm{~s}$, held for an additional $2 \mathrm{~s}$ to allow excess solution to drip from the stem piece, and reweighed. The ratio of the weight adhering SCG solution to weight of the stem piece was calculated. The mean weight $( \pm \mathrm{SD})$ of stem pieces was $100.8 \pm 15.0 \mathrm{mg}$ for Hedera helix, $186.1 \pm$ $36.9 \mathrm{mg}$ for Ternstroemia gymnanthera, and $277.9 \pm 62.3 \mathrm{mg}$ for Elaeagnus xebbingei. There were 10 replications per treatment for each species.

Data were analyzed using the GLM procedure of SAS (Version 9.2; SAS Institute Inc., Cary, NC). The resulting regression models were assessed using coefficients of determination $\left(r^{2}\right)$ and $P$ values from lack-of-fit tests. The coefficient of determination, $r^{2}$, indicates the proportionate reduction associated with the use of an explanatory variable, whereas the F test for lack of fit, which requires repeated observation at one or more levels of the explanatory variable, is a formal test for determining whether a specific type of regression function adequately fits the data (Neter et al., 1996). The SCG rate providing maximum adhesion in each experiment was determined by setting the first derivative of each regression equation equal to zero and solving for the SCG rate. Partial derivatives were used in Expt. 2 to solve for the SCG rates for solutions prepared with DI water and solutions prepared with auxin.

\section{Results and Discussion}

Results from Expt. 1 established that the SCG rate providing maximum adhesion (based on the ratio of SCG solution weight to stem piece weight) was likely to fall between 11 and $16 \mathrm{~g} \cdot \mathrm{L}^{-1}$ (Fig. 1A); thus, this 

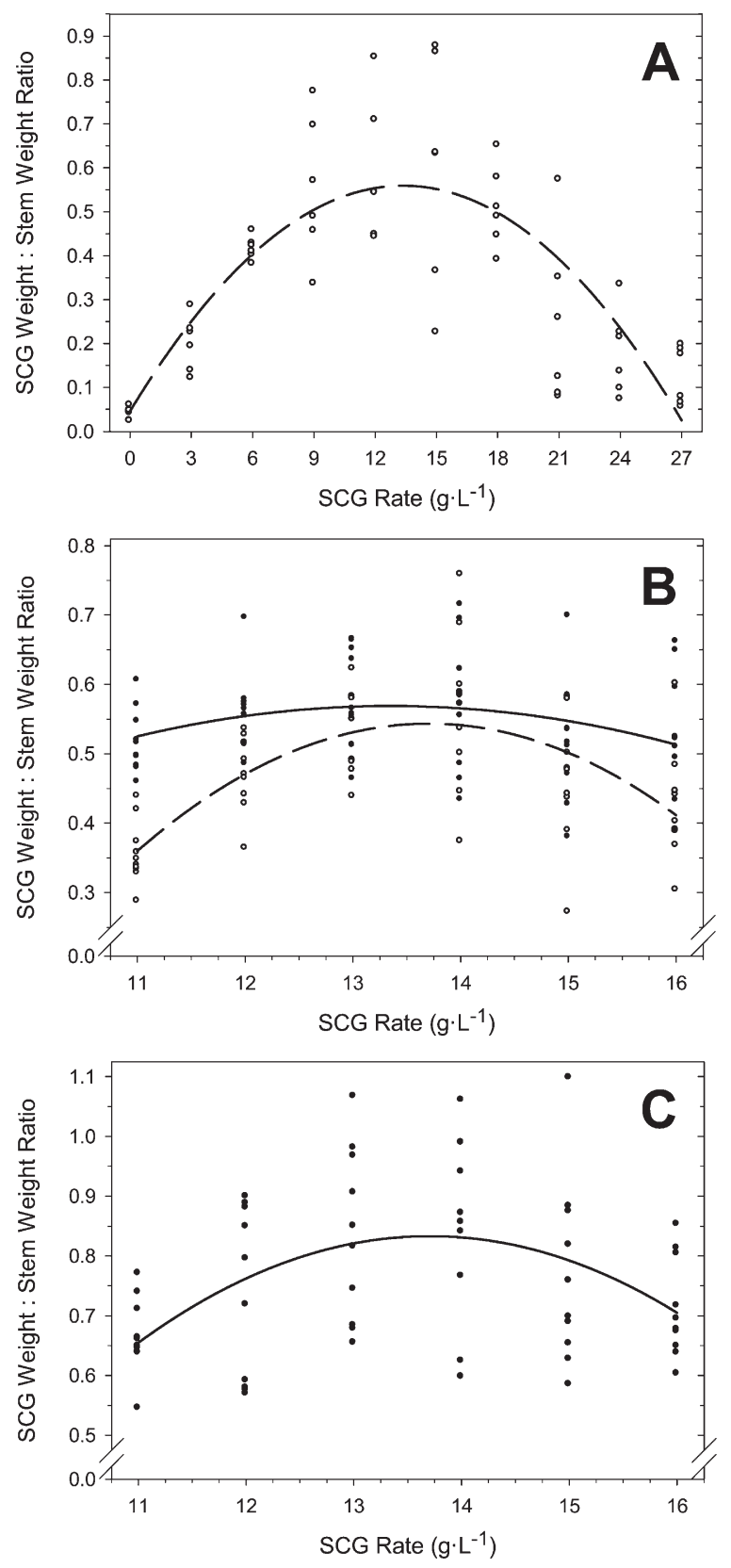

Fig. 1. Data points and regression lines showing the ratio of sodium cellulose glycolate (SCG) solution weight to stem piece weight when $3.75-\mathrm{cm}$ stem pieces of Hedera helix (A), Ternstroemia gymnanthera (B), and Elaeagnus Xebbingei (C) were dipped to a depth of $2.5 \mathrm{~cm}$ into solutions of SCG at selected rates to test for adhesion of the SCG solutions onto the stem pieces. SCG solutions were prepared with deionized water (open circles and dashed lines) or an auxin solution as a $10 \%$ dilution of Dip 'N Grow (solid circles and solid lines). range of SCG rates was used in Expts. 2 and 3. The model selected for Expt. 1 (Table 1) accounted for almost two-thirds of the variability in the data $\left(r^{2}=0.64\right)$. Although the lack-of-fit test indicated this model was suitable for the data, its somewhat low $P$ value (0.0705) appears to be the result of less suitable fit at the lower and higher rates of SCG and heterogeneous variance at different levels of SCG rate (Fig. 1A). The $r^{2}$ values for models selected for Expts. 2 and 3 (0.41 and 0.21 , respectively) were lower than for Expt. 1; however, $P$ values for the lack-of-fit tests ( 0.4012 and 0.7234 , respectively) indicated that the models provided a good fit to the data despite the variability in the data values at each rate of SCG indicated by the $r^{2}$ values.

Greater adhesion of SCG solutions occurred when solutions were prepared with the alcohol-based auxin formulation compared with solutions prepared with DI water, although this difference was less around the SCG rate of maximum adhesion (Fig. 1B). The greater adhesion ratios obtained in Expt. 3 (Fig. 1C) were possibly the result of the more rough-textured surface of the Elaeagnus xebbingei stems in comparison with the relatively smooth stems of Hedera helix and Ternstroemia gymnanthera. The maximum adhesion ratios (with 95\% confidence intervals) obtained were $0.559(0.503-0.618)$ using DI water in Expt. 1, 0.543 (0.513-0.574) using DI water, $0.569(0.539-0.599)$ using the auxin formulation in Expt. 2, and 0.833 (0.7830.884 ) using the auxin formulation in Expt. 3.

Maximum adhesion of SCG solutions occurred over a range of SCG rates from 13.35 to $13.71 \mathrm{~g} \cdot \mathrm{L}^{-1}$ with an overall average rate of $13.5 \mathrm{~g} \cdot \mathrm{L}^{-1}$ (Table 1 ). Whereas this was the rate used in the authors' rooting study (Blythe and Sibley, 2007), commercial propagators may wish to test other rates to determine the viscosity that best suits their crops and propagation processes. Enhanced adhesion of auxin solutions can potentially allow use of lower rates of auxin than those used in conventional auxin solutions.

With use of SCG at an appropriate rate for preparation of auxin solutions, auxin effectiveness can be enhanced, leading to increased efficiency in cutting propagation. SCG provides propagators with an additional tool for propagating the wide assortment of ornamental crops grown by commercial

Table 1. Regression equations modeling the ratio of sodium cellulose glycolate (SCG) solution weight to stem piece weight when 3.75-cm stem pieces of Hedera helix (Expt. 1), Ternstroemia gymnanthera (Expt. 2), and Elaeagnus Xebbingei (Expt. 3) were dipped to a depth of $2.5 \mathrm{~cm}$ into solutions of SCG at selected rates to test for adhesion of the SCG solutions onto the stem pieces. ${ }^{2}$

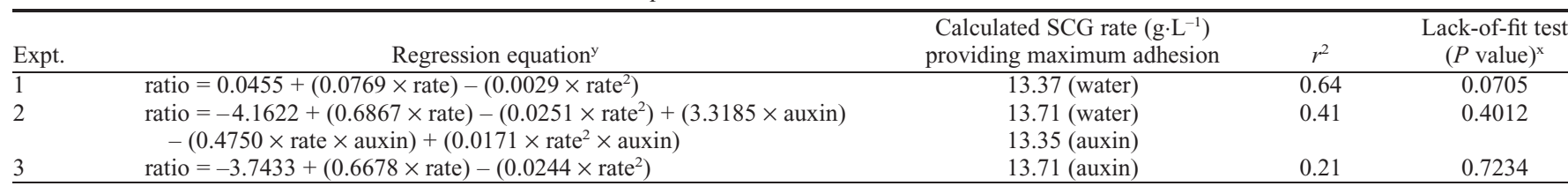

${ }^{2}$ SCG solutions were prepared with deionized (DI) water alone (Expt 1.), both DI water and an auxin solution (Expt. 2), or auxin solution alone (Expt. 3). "In the regression equations, "rate" refers to SCG rate $\left(\mathrm{g} \cdot \mathrm{L}^{-1}\right)$ and "auxin" refers to SCG solutions prepared with a $10 \%$ dilution of Dip 'N Grow Liquid Rooting Concentrate (Dip 'N Grow, Inc., Clackamas, OR) rather than DI water. There were 10 replicates per SCG rate (Expts. 1 and 3) or SCG rate/solution type treatment

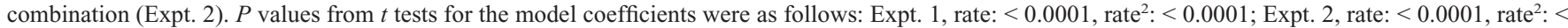
0.0001 , auxin: 0.0015 , rate $\times$ auxin: 0.0024, rate $^{2} \times$ auxin: 0.0031 ; Expt. 3, rate: 0.0004 , rate ${ }^{2}: 0.0005$.

${ }^{\mathrm{x}} \mathrm{A}$ lack-of-fit test $P$ value $>0.05$ indicates satisfactory fit of the model to the data. 
nurseries. SCG may also have potential in the preparation and application of other plant growth regulators.

\section{Literature Cited}

Beeson, R.C., Jr. 2000. Putting the speed back in quick-dip auxin application. Proc. Southern Nursery Assoc. Res. Conf., 45th Annu. Rpt. p. 298-300.

Blythe, E.K. and J.L. Sibley. 2007. Sodium cellulose glycolate as a thickening agent for liquid auxin formulations can enhance rooting of stem cuttings. J. Environ. Hort. 25:126-130.

Blythe, E.K., J.L. Sibley, K.M. Tilt, and J.M. Ruter. 2004. Auxin application to stem cuttings of selected woody landscape plants by incorporation into a stabilized organic rooting substrate. J. Environ. Hort. 22:63-70.
Blythe, E.K., J.L. Sibley, K.M. Tilt, and J.M. Ruter. 2007. Methods of auxin application in cutting propagation: A review of 70 years of scientific discovery and commercial practice. J. Environ. Hort. 25:166-185.

Childs, K. and R.C. Beeson, Jr. 2001. Rooting 'Little Gem' magnolia: Cell-U-Wett or water? Proc. Southern Nursery Assoc. Res. Conf., 46th Annu. Rpt. p. 371-373.

Gasanov, G.N. and N.R. Magomedov. 2004. Optimization of cultivation of cereal fodder crops under arid condition of the south of Russia. Kormoproizvodstvo 6:14-17.

Hartmann, H.T., D.E. Kester, F.T. Davies, Jr., and R.L. Geneve. 2002. Hartmann and Kester's plant propagation: Principles and practices. 7th Ed. Prentice Hall, Upper Saddle River, NJ.

Joint FAO/WHO Expert Committee on Food Additives. 1966. Specifications for the identity and purity of food additives and their toxicological evaluation: Some antimicrobials, antioxidants, emulsifiers, stabilizers, flour-treatment agents, acids, and bases. Ninth Rpt. of the Joint FAO/ WHO Expert Committee on Food Additives, Rome, 13-20 Dec. 1965. FAO Nutr. Meetings Rpt. Ser., No. 40; Tech. Rpt. Ser. (World Health Org.), No. 339.

Kirk, I.W. 2003. Spray mix adjuvants for spray drift mitigation-Progress report. Amer. Soc. Agr. Eng. Annu. Mtg., Las Vegas, NV, 27-30 July 2003. Paper No. 031030.

Neter, J., M.H. Kutner, C.J. Nachtsheim, and W. Wasserman. 1996. Applied linear statistical models. 4th Ed. McGraw-Hill, New York, NY.

Shavit, U., A. Shaviv, and D. Zaslavsky. 1995. Solute diffusion coefficient in the internal medium of a new gel based controlled release fertilizer. J. Control. Release 37:21-32. 